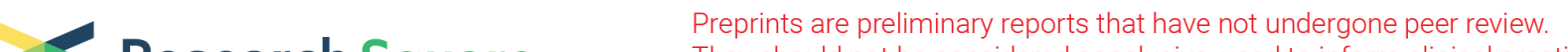 Research Square They should not be considered conclusive, used to inform clinical practice, or referenced by the media as validated information.
}

\section{Impacts of Late-Spring North Eurasian Soil Moisture Variation on Summer Rainfall Anomalies in Northern East Asia}

\section{Yinghan Sang ( 1128 sang@sina.cn)}

Nanjing University of Information Science and Technology

Hong-Li Ren

State Key Laboratory of Severe Weather https://orcid.org/0000-0001-7194-0567

\section{Yi Deng}

Georgia Institute of Technology

\section{Xiaofeng Xu}

China Meteorological Administration

\section{Xueli Shi}

China Meteorological Administration

Shuo Zhao

State Key Laboratory of Severe Weather

\section{Research Article}

Keywords: soil moisture, summer rainfall, North Eurasia, northern East Asia

Posted Date: April 20th, 2021

DOI: https://doi.org/10.21203/rs.3.rs-419930/v1

License: (1) This work is licensed under a Creative Commons Attribution 4.0 International License. Read Full License

Version of Record: A version of this preprint was published at Climate Dynamics on September 24th, 2021. See the published version at https://doi.org/10.1007/s00382-021-05973-9. 


\section{Abstract}

This paper reports findings from a diagnostic and modeling analysis that investigates the impact of the late-spring soil moisture anomaly over North Eurasia on the boreal summer rainfall over northern East Asia (NEA). Soil moisture in May in the region from the Kara-Laptev Sea coasts to Central Siberian Plateau is found to be negatively correlated with the summer rainfall from Mongolia to Northeast China. The atmospheric circulation anomalies associated with the anomalously dry soil are characterized by a pressure dipole with the high-pressure center located over North Eurasia and the low-pressure center over NEA, where an anomalous lower-level moisture convergence occurs, favoring rainfall formation. Diagnoses and Modeling experiments demonstrate that the effect of the spring low soil moisture over North Eurasia may persist into the following summer through modulating local surface latent and sensible heat fluxes, increasing low-level air temperature at higher latitudes, and effectively reducing the meridional temperature gradient. The weakened temperature gradient could induce the decreased zonal wind and the generation of a low-pressure center over NEA, associated with a favorable condition of local synoptic activity. The above relationships and mechanisms are vice versa for the prior wetter soil and decreased NEA rainfall. These findings suggest that soil moisture anomalies over North Eurasia may act as a new precursor providing an additional predictability source for better predicting the summer rainfall in NEA.

\section{Introduction}

As an important part of the surface hydrological cycle, soil moisture plays a vital role in global landatmosphere interactions (Seneviratne et al. 2010). By influencing numerous physical processes in landatmosphere interactions, soil moisture has considerable impacts on climate elements, such as precipitation and temperature. Similar to ocean, soil moisture has the character of "memory" (Koster et al. 2001; Shinoda 2001; Ruosteenoja et al. 2018). Previous studies have indicated that soil moisture signals in middle and high latitudes of the Northern Hemisphere could last 1-3 months and have a lagged effect on atmospheric circulation anomalies, which will further influence climate elements (Shukla and Mintz 1982; Dirmeyer et al. 2009). As a result of its memory effect, soil moisture as a precursor is instructive for short-term climate prediction.

The climatic effects of soil moisture have been extensively studied during the past few decades (e.g., Yeh et al. 1984; Chahine 1992; Dai et al. 1999; Koster et al. 2001, 2003; Seneviratne et al. 2006; Sato and Nakamura 2019). Based on highly controlled numerical experiments by different climate models, Koster et al. (2004) proposed that there are specific "hot spots" with strong land-atmosphere couplings, where soil moisture anomalies have substantial impacts on precipitation through influencing evaporation and other surface energy fluxes. In recent years, studies have shown that better precipitation simulations and predictions may be expected with the improved accuracy of initial soil moisture, which could exert distinct influences on precipitation change (Shi et al. 2021). Wu and Zhang (2013), based on Weather Research and Forecasting (WRF) model simulations, explored the role of soil moisture playing in the formation of the flood and drought over East China in the summers of 1998 and 1999, and showed that soil moisture 
substantially contributes to both droughts and floods over northern East China through its memory. These results could help improve the skill of seasonal precipitation prediction.

However, owing to the deficiencies of reliable large-spatial and long-term measurement of soil moisture, many studies have had to rely on model simulations to investigate the relationship between soil moisture and climate variability (Wu and Dickinson 2004; Kim and Hong 2007). Therefore, further diagnoses based on the increasing amounts of new observations as well as the latest reanalysis products are still needed. Moreover, previous studies have mainly focused on the local climate effects of soil moisture anomalies and rarely on the potential remote impacts. Xue et al. (2018) demonstrated that the upstream land surface, by influencing heat fluxes, may affect the subsequent downstream droughts/floods in East Asia. This study further demonstrated that such effects are not only constrained within local areas but also extended downstream.

The East Asian summer rainfall directly influences the economy and human wellbeing across the region. However, increasing the accuracy of seasonal prediction of summer rainfall in East Asia has always posed considerable challenges, particularly in its northern region (Ding and Chan 2005; Wang 2006; Zhou and Zou 2010). Some studies have shown that summer precipitation in East China is influenced by a number of factors, including soil moisture, which is particularly important (Zuo et al. 2007; Dai et al. 2010; Zhang et al. 2016a). However, the relationship between soil moisture and precipitation illustrated in these studies has generally been constrained to include only the local effects within East China.

North Eurasia covering a vast area is located in the upper reaches of northern East Asia (NEA) and the soil moisture there has the seasonal scale of memory (Dirmeyer et al. 2009). Given the relatively low accuracy of summer rainfall prediction over NEA, the soil moisture variability over North Eurasia and its possible impacts on the climate downstream are worthy of examination for a potential future application in the seasonal prediction of summer rainfall. In this study, we aimed to investigate the linkage between summer (June-August, JJA) precipitation anomalies in NEA and the precedent late-spring (May) soil moisture anomalies upstream in North Eurasia through both observational data diagnoses and numerical model experiments. The results may provide new insights on how to improve the prediction of summer precipitation in NEA.

The remainder of the paper will be organized as follows. Section 2 describes data, methods and climate model used here, while Section 3 discusses the relation of the late-spring soil moisture anomalies with the summer rainfall anomalies in NEA. Section 4 presents an analysis of the physical mechanism through which the soil moisture affects the atmospheric circulation connected with rainfall. The results of numerical model experiments are given in Section 5. Finally, the summary and discussions are provided in Section 6.

\section{Data, Methods And Numerical Model}

\subsection{Data}


Due to the lack of reliable SM gauge measurement datasets covering large-domain and long-term scales in situ observations, assimilation and reanalysis products are generally two kinds of alternative SM datasets available for researches. Assimilated soil moisture data products such as the Global Land Data Assimilation System (GLDAS) use advanced land surface modeling and data assimilation techniques to provide combined satellite- and ground-based observational products for soil moisture research (Rodell et al. 2004). In the current study, the two versions of GLDAS (v2.0 and v2.1) data were combined to form the monthly mean near-surface $(0-10 \mathrm{~cm})$ soil moisture dataset on a $0.25^{\circ}$ latitude $\times 0.25^{\circ}$ longitude grid covering the period of 1980-2018, from the Goddard Earth Sciences Data and Information Services Center. In addition, soil moisture on the first level $(7 \mathrm{~cm})$ from the European Centre for Medium-Range Weather Forecasts (ECMWF) reanalysis (ERA) Interim/Land data (Balsamo et al. 2015), which includes the land reanalysis product using the latest ECMWF land surface model with numbers of parameterization improvements in the land surface scheme, was used as a reference to make our conclusions more robust. Correspondingly, the surface heat fluxes data were also chosen from the GLDAS and ERA-Interim/Land. Unless stated otherwise, the related figures and indices displayed in this paper were calculated using the GLDAS. Monthly mean precipitation data used here are from the CPC (Climate Prediction Center) Merged Analysis of Precipitation (CMAP, Xie and Arkin 1997). The daily and monthly atmospheric circulation field data (e.g., sea level pressure (SLP), geopotential heights, zonal and meridional wind) were obtained from the National Center for Environmental Prediction and Department of Energy Reanalysis 2 (NCEP-DOE R2, Kanamitsu et al. 2002) covering the period 1980-2018.

\subsection{Methods}

To demonstrate the dominant coupled modes between the summer rainfall in NEA and the preceding soil moisture upstream in North Eurasia, we used the singular value decomposition (SVD) analysis (also known as maximum covariance analysis) (Wallace et al. 1992; Von Storch and Zwiers 1999). Other commonly used statistical analysis techniques and metrics such as Pearson correlation and linear regression were also adopted in this study. All the data were linearly detrended and the annual cycle was removed to focus on climate anomalies. Furthermore, the Eady growth rate (Eady 1949) is calculated using daily data to represent the baroclinic instability.

\subsection{Numerical model}

The Community Earth System Model version 1.2.2 (CESM 1.2.2), a state-of-the-art coupled climate model, with interactive components of the atmosphere, land, ocean and sea ice, was used to detect the effects of the preceding soil moisture anomalies in this study. The Version 4.0 of Community Land Model (CLM 4.0) is the land component of CESM 1.2.2, which mainly includes the processes of surface energy transportation, hydrology and biogeochemical cycles (Lawrence et al. 2011). The Community Atmospheric Model version 4.0 (CAM 4.0, Eaton 2010) possessing a horizontal resolution of $1.9^{\circ}$ latitude $\times 2.5^{\circ}$ longitude and 26 vertical levels is the atmospheric component of CESM 1.2.2. Details of the experimental design are provided in Section 5. 


\section{Relationship Between Nea Summer Rainfall And The Preceding Soil Moisture In North Eurasia}

\subsection{The statistical relationship}

Severe flood and drought events occurred over Northeast China in the summers of 2013 and 2015, respectively, and caused substantial economic losses (Yang and He 2013; Wang et al. 2016). We found that the summer rainfall anomalies are well associated with the precedent late-spring soil moisture anomalies in North Eurasia. As shown in Figure 1, the negative soil moisture anomalies occur along with the positive anomalies relating to the summer rainfall downstream, and vice versa. To confirm whether or not these negative correlations are only rare cases, we applied SVD at a longer time scale ranging from 1980 to 2018. Figure 2 presents the results of the SVD analysis of soil moisture anomalies in May over North Eurasia and precipitation anomalies in summer over NEA. The first SVD (SVD1) modes of the precipitation anomalies in summer and soil moisture anomalies in May account for $66.2 \%$ of their covariance. Both of the two variables depict the same sign of homogeneous correlations in their respective areas (Figures $2 \mathrm{a}$ and $2 \mathrm{c}$ ), demonstrating that the late-spring soil moisture and summer precipitation are characterized by consistent variations. Figures $2 b$ and $2 d$ show that the patterns of SVD1 heterogeneous correlations are similar to those of homogeneous correlations, indicating a close connection between these two fields. Specifically, for the North Eurasian soil moisture anomalies in May, the SVD1 spatial pattern shows significantly negative correlations covering Central Siberian Plateau and the coastal areas of Kara-Laptev Sea. The spatial pattern of summer precipitation anomalies features pronounced positive correlations from Mongolia to Northeast China, the sign of which is opposite to that of soil moisture. The SVD1 modes calculated by ERA-Interim/Land (figure not shown) resemble those of GLDAS; however, the explained variance is lower (35.6\%). Figure 2e presents the two extension coefficient time series corresponding to the SVD1 modes with an apparent interannual variability. The coherent decadal variations are significantly negatively correlated ( $r=0.71$, significant at the $95 \%$ confidence level of Student's $t$-test).

Note that actual anomalies of precipitation and soil moisture in each year are directly proportional to the SVD pattern values multiplied by their corresponding time series for the year. When both the time series of precipitation and soil moisture are positive, the soil moisture in North Eurasia will be negatively anomalous and the precipitation over NEA will positively anomalous. This indicates that the precedent dry soil moisture in North Eurasia is significantly related to the summer increased precipitation in NEA, and vice versa. To more precisely describe the variations of the late-spring soil moisture and downstream summer rainfall, we selected key regions of soil moisture $\left(58^{\circ} \mathrm{N}-72^{\circ} \mathrm{N}, 90^{\circ} \mathrm{E}-123^{\circ} \mathrm{E}\right)$ and precipitation $\left(45^{\circ} \mathrm{N}-51^{\circ} \mathrm{N}, 107^{\circ} \mathrm{E}-130^{\circ} \mathrm{E}\right)$, and defined the time series of averaged soil moisture anomalies in May and averaged precipitation anomalies in JJA over their respective boxes as the soil moisture and precipitation indices, respectively. The correlation coefficients between the two new indices and the corresponding SVD1 time series are -0.81 and 0.70 for the soil moisture and precipitation, respectively, suggesting the indices defined by box-average can realistically represent the primary coupled and individual variations of the two variables. More importantly, the correlation coefficient between the two indices is -0.72 
(significant at the 0.05 level, Figure $2 \mathrm{f}$ ), which is almost the same as the negative correlation coefficient between the two SVD1 time series. This further indicates that the summer rainfall anomalies in NEA are significantly negatively correlated with the precedent upstream soil moisture anomalies in late spring over North Eurasia. Furthermore, these two indices remain highly correlated after removal of the 5-year running mean to eliminate the influence of the decadal background ( $r=-0.78$, significant at the 0.05 level), which demonstrates that these two variables are highly correlated not only at the decadal scale, but also at the interannual scale.

\subsection{The atmospheric circulation anomaly related to the preceding soil moisture anomalies}

We further explored whether the late-spring soil moisture anomalies are linked to atmospheric circulation and further impact the downstream rainfall variation over NEA in the following summer. Figure 3 presents patterns of SLP and geopotential height anomalies in JJA regressed against $-1 \times$ soil moisture index (henceforth the minus soil moisture index). In summer, the statistically significant below-normal SLP, which is conducive to the formation of positive rainfall anomalies, can be detected around NEA, extending from Mongolia to Northeast China (Figure 3a). At the same time, the area from the coasts of Kara-Laptev Sea to Central Siberian Plateau, including the key region of soil moisture, is covered by significantly high SLP. Similarly, the geopotential height anomalies at 850-hPa level (Figure 3b) also show a dipole pattern over Eurasia that highly resembles the pattern presented in SLP. That is, the key regions of precipitation and soil moisture clearly show subnormal and above-normal pressures, respectively. The similar pattern emerges to the heights of 500 and $200 \mathrm{hPa}$ (Figures 3c and 3d) with significant negative anomalies over the key region correlated with precipitation (although the range of negative values shows some shrinkage). Therefore, the summer atmospheric circulation anomalies over NEA are clearly related to the earlier upstream soil moisture in late spring over North Eurasia and further likely affect the summer precipitation. Specifically, the negative North Eurasian soil moisture anomalies intimately correspond to the dipole pattern of "positive in the north and negative in the south" in atmospheric circulation anomalies. Correspondingly, the key region in NEA where the summer precipitation is highly correlated with the North Eurasian soil moisture is occupied by subnormal pressure from the lower to upper levels. This quasi-barotropic anomaly structure favors the formation of positively anomalous summer rainfall in this area. Similarly, the positive soil moisture anomalies upstream are supposed to be related with the positive pressure anomalies and the decreased rainfall over NEA.

Figures $4 \mathrm{a}$ and $4 \mathrm{~b}$ show the anomalies of $850-\mathrm{hPa}$ wind and vertically integrated water vapor fluxes in summer regressed against the minus SM index, respectively. Both of the two variables show there is a significantly anomalous cyclonic circulation pattern covering the area from Mongolia to Northeast China, which is conducive to the atmospheric convergence and upward motion favoring the increase of rainfall. There are two significant transport channels to NEA: one is from Bay of Bengal and South China Sea merging into Southwest China, and the other is from the ocean east of Japan, providing the flush water vapor condition for increasing the rainfall in NEA. 
Storm track activity is also shown here to examine the effect of soil moisture on the NEA circulation. Figure $4 \mathrm{c}$ gives the differences of JJA synoptic-scale meridional wind variance at $850 \mathrm{hPa}$ between lowsoil moisture (indices less than one standard deviation) years and high-soil moisture (indices larger than one standard deviation) years as representing the storm track through using a 2-8-d band-passed filter. It can be seen that NEA is featured with positive values while the north is featured with negative ones. By further regressing the summer Eady growth rate against the minus soil moisture index (Figure 4c), we could find that the pattern is reasonably consist with that of storm track. It suggests that the background circulation anomalies (i.e., zonal wind, high/low pressure) related with the negative soil moisture anomalies will lead to the strengthened baroclinic instability over NEA and the weakened one in the north. Therefore, the synoptic eddies will be more active over NEA due to the strengthened baroclinic instability (Hoskins and Valdes 1990). Previous studies have showed that the synoptic eddies, such as the Northeast-China Cold Vortex at mid-high latitudes of East Asia in summertime, are closely responsible for heavy rain over the northeastern and northern China (He et al. 2006; Zhou et al. 2020). The zonal wind anomalies at $700-\mathrm{hPa}$ (indicating the steering flow, Figure 4d) show that the westerlies over NEA are increased. This enhanced steering flow is favorable to the local genesis and downstream propagation of synoptic eddies to increase the rainfall in NEA. Therefore, the statistically significant relationship between the anomalies of the summer precipitation in NEA and the late-spring soil moisture over North Eurasia is linked with the dipole patterns of anomalous pressure, cyclonic/anticyclonic circulation and related water vapor transport. In the following section, we will discuss the possible mechanisms by which the preceding soil moisture anomalies can affect the summer circulation and rainfall in NEA.

\section{Physical Mechanisms}

Soil moisture could affect precipitation through both its local and nonlocal effects (Seneviratne et al. 2010; Li and Xue 2014; Li et al. 2016). In the case of local effects, the increase of soil moisture can lead to increased evapotranspiration, including vegetation transpiration and surface evaporation, and thus an increased supply of water vapor into atmosphere, which is conducive to the increase of precipitation at local scale (Koster et al. 2003). For the nonlocal effects, the change of surface temperature in the continental monsoon region caused by soil moisture variation would affect the thermal contrast between land and ocean, and further modulate the large-scale monsoonal circulation associated precipitation anomalies at larger scale (Zhang et al. 2016b). At these two different scales, the soil moisture anomalies strongly affect atmosphere through changing surface heat fluxes. Specifically, wet soil leads to a higher surface latent heat flux through evapotranspiration at the expense of the surface sensible heat flux, which further affects the atmosphere above (Dirmeyer et al. 1999; Koster et al. 2003; Xue et al. 2004, 2006). Thus, it is necessary to further investigate whether the summer atmospheric anomalies discussed above are resulted from the changes in the thermal conditions caused by the effects of soil moisture on surface heat fluxes.

Figure 5a presents the North Eurasian soil moisture anomalies in JJA regressed against the minus soil moisture index. The area from the West Siberian Plain to Central Siberian Plateau, including the key soil moisture region, is featured with significantly negative soil moisture anomalies, which validates the 
finding that the late-spring soil moisture signals could persist into the following summer. In addition, the soil moisture indices of May and JJA are highly autocorrelated ( $r=0.89$, significant at the 0.05 level), indicating that the memory is of seasonal scale.

Figures $5 \mathrm{~b}$ and $5 \mathrm{c}$ show the North Eurasian JJA air temperature anomalies at the surface and at $2 \mathrm{~m}$ height regressed against the minus soil moisture index, respectively. The whole of North Eurasia is distinguished by a positively anomalous temperature in summer, especially the key soil moisture region, illustrating that the negative soil moisture anomalies in May over North Eurasia are accompanied by the increased lower-level air temperature at the high latitudes, and vice versa. The distributions of surface heat fluxes anomalies regressed against the minus soil moisture index are shown in Figure 6. Most of North Eurasia is characterized by significantly negative latent heat flux anomalies in summer (Figure 6a). This suggests that the persistent abnormally dry soil moisture signal from May to JJA could result in the negative anomalies of latent heat fluxes over the same key soil moisture region in summer, and vice versa. The patterns of sensible heat flux anomalies also show clear features. Figure $6 \mathrm{~b}$ shows significantly positive sensible heat flux anomalies appear over nearly all of North Eurasia. The sign of sensible heat flux anomalies is opposite to that of latent heat flux anomalies, which is consistent with the findings of previous studies (Koster et al. 2006; Seneviratne et al. 2010). The positive sensible heat flux anomalies will directly increase the air temperature at lower atmosphere layers above the key soil moisture region, as shown by the air temperature in latitude-height section along $105^{\circ} \mathrm{E}$ in Figure $6 \mathrm{c}$. The increased air temperature in North Eurasia will lead to the decrease of meridional temperature gradient between middle and high latitudes. Simultaneously, the cooling above the key precipitation region further intensifies the decreased temperature gradient. As a result, according to the principle of thermal wind, the zonal wind at lower levels north of NEA is weakened and present the character of an anomalous easterly (Figure $6 \mathrm{~d}$ ). Such conditions can be favorable for the formation of a cyclonic circulation south of the easterly where NEA is located (Figure 4a), leading to the dipole pattern of geopotential height over Eurasia, which further increases the NEA summer rainfall. Previous studies have suggested that the weakened zonal wind at middle and high latitudes favors the development and persistence of the meridional component of atmospheric circulation in summer, such as blocking highs, which play a vital role in enhancing rainfall in East Asia (Murray and Simmonds 1995; Tang et al. 2013; Yao et al. 2017; Zhang et al. 2018). Therefore, by affecting the surface heat fluxes, the soil moisture anomalies over North Eurasia will influence the lower-layer air temperature, followed by the meridional temperature gradient, and finally the atmospheric circulation related to the Eurasian summer precipitation.

\section{Model Experiments}

In this section, we present an assessment of the influences of the precedent soil moisture anomalies in North Eurasia to the atmospheric circulation related to the NEA summer precipitation downstream and investigate the associated physical processes establishing such connections using model experiments conducted with the CESM 1.2.2. Three sets of experiments forced by prescribed climatological monthlymean SST and sea-ice concentration were performed. The control run (exp_CTL) was integrated for 50 model years and the first 10 years were discarded for spin up. The high-soil moisture experiment 
(exp_HSM) and low-soil moisture experiment (exp_LSM) are two sets of sensitivity experiments used for detecting the influences of soil moisture anomalies in North Eurasia. The surface soil moisture anomalies in each grid over the soil moisture key region $\left(58^{\circ}-72^{\circ} \mathrm{N}, 90^{\circ}-123^{\circ} \mathrm{E}\right)$ were obtained by the maximum minus the minimum of 40-year control run. The anomalies were added and subtracted onto the outputs of exp_CTL, which are regarded as the initial conditions of exp_HSM and exp_LSM, respectively. For the initial conditions of exp_HSM, if the values of soil moisture are larger than the maximum of the 40 model years of exp_CTL, then they were assigned as the maximum. Similarly, in exp_LSM, zero was assigned to all values less than zero. Each sensitivity experiment consisting of 40 ensemble members was integrated from 1 May to 31 August. The responses of the model to the soil moisture anomalies are defined as the ensemble mean differences between exp_LSM and exp_HSM.

Figure 7 displays the ensemble mean differences in summer precipitation and atmospheric circulation between exp_LSM and exp_HSM. Figure 7a shows that NEA is featured with positive anomalous rainfall. Significantly negative SLP anomalies covering the area ranging from Mongolia to Northeast China are favorable for positive rainfall anomalies (Figure 7b). At the same time, North Eurasia, which includes the eastern part of the key soil moisture region, is characterized by heavy SLP. This the dipole pattern of "positive in the north and negative in the south" is similar to the result in Section 3.2. At the height field of $850 \mathrm{hPa}$ (Figure 7c), although the range and intensity of simulated positive geopotential height over North Eurasia tend to reduce, relative to the SLP pattern, NEA is still featured with significantly negative anomalies contributing to the positive precipitation anomalies. The $850-\mathrm{hPa}$ wind matches well with the height field (Figure 7d). A clear anticyclone anomaly appears above the key soil moisture region. In the downstream region of the anomaly, there is a significant cyclonic shear circulation above NEA that will enhance the convergence and upward motion at lower level and further promote the formation of positive rainfall anomalies. The ensemble-mean difference of the vertically integrated water vapor fluxes (Figure 7e) shows that NEA is a zone of significant convergence. The pattern of the divergence of vertically integrated water vapor fluxes clearly shows that the regions south of the Lake Baikal ranging from Mongolia to Northeast China are characterized by significantly negative divergence anomalies (Figure 7f), favoring the positive rainfall anomalies.

Figure 8a shows that the latent heat fluxes over North Eurasia in summer simulated by exp_LSM are significantly lower than that of exp_HSM. Contrary to the latent heat fluxes, the responses of sensible heat fluxes indicate that the positive anomalies cover North Eurasia (Figure 8b) resulting in the increased air temperature at lower atmosphere levels and the decreased meridional temperature gradient between middle and high latitudes over Eurasia (Figure 8c) and leading to the weakened zonal wind in the middle latitudes (Figure 8d). This anomalous easterly will generate the cyclonic shearing circulation above NEA and then the dipole pattern spanning East Asia. Clearly, the results of the sensitivity experiments by the CESM 1.2.2 are reasonably consistent with the main features of the observational diagnoses, which validates to some degree our new findings that the summer circulation anomalies related to the rainfall anomalies in NEA can be influenced by the late-spring soil moisture anomalies over North Eurasia. 


\section{Summary And Discussions}

In this study, we investigated the relation between the late-spring soil moisture over North Eurasia and summer rainfall over NEA based on the observations and numerical model experiments. The SVD1 modes of NEA precipitation in summer and North Eurasian soil moisture in May with $66.2 \%$ of their explained variance show that both of the fields depict the same sign of heterogeneous correlations in their respective areas, which is very similar to the patterns of homogeneous correlations. In particular, the soil moisture anomalies over the upstream regions in May show a significantly negative correlation with the following summer rainfall anomalies over the regions from Mongolia to Northeast China. Furthermore, the two extension coefficient time series corresponding to SVD1, which reveal nearly consistent interannual and decadal variations with each other, are highly correlated with the coefficient of 0.71 . The late-spring soil moisture index and summer precipitation index calculated by the method of box-average, are also negatively correlated $(r=-0.72)$. We further found that the late-spring negative soil moisture anomalies over North Eurasia are associated with the dipole mode of geopotential height pattern over the whole of East Asia in summer: the key region of soil moisture is occupied by abovenormal pressure, and the key region of precipitation is covered by lower pressure anomalies that favor the formation of the positive rainfall anomalies. Concurrently, 850-hPa wind displays significant cyclone anomalies that could enhance the convergence movement to boost the rainfall over NEA. The water vapor fluxes show two significant water vapor transport channels to the key region related to precipitation. At the same time, the background circulation anomalies related to the abnormal soil moisture will also influence the baroclinic instability and the synoptic activity, then affecting the rainfall anomaly distribution. Hence, the related conditions of circulation lead by abnormal upstream dryer (wetter) soil will enhance (decrease) the precipitation over NEA.

Upon further analysis, we identified the mechanism by which soil moisture anomalies can generate the appropriate atmospheric circulation that affects the downstream precipitation. We found that the abnormal soil moisture signal in May will persist into the following summer and consistently influence the surface heat fluxes. In particular, the dryer soil in North Eurasia will lead to the negative latent heat flux anomalies and positive sensible heat flux anomalies. Correspondingly, the increased air temperature in the lower atmosphere layers will narrow the meridional temperature gradient between middle and high latitudes, then promote the anomalous easterly and generate the cyclonic circulation over NEA and finally generate the dipole pattern favorable for the positive precipitation anomalies in NEA. The cooling effect of the increased rainfall further decreases the meridional temperature gradient and promotes this cyclic process. The influences of the wetter soil are vice versa. Thus, changes to the thermal conditions by affecting the heat fluxes are a vital pathway by which soil moisture influences the atmospheric circulation. The physical processes discussed above are summarized in Figure 9.

The results of the ensemble mean differences between the exp_LSM and exp_HSM are reasonably consistent with those of observational diagnoses, except that the high-pressure systems are not significant at higher levels and the positions of circulation center lean toward the south. By analyzing the climatology, we found that the relatively lower pressure and the more southerly located wind systems in 
the model simulation (figure not shown) may lead to the situations above. In general, the simulated atmospheric circulation responding to the precedent low-soil moisture anomalies in late spring shows that NEA is occupied by abnormally low pressure and convergence motions promoting the positive rainfall anomalies in summer. The abnormally dry soil in May is accompanied by negative latent heat and positive sensible heat flux anomalies. Subsequently, the increased air temperature in North Eurasia will decrease the meridional temperature gradient between middle and high latitudes and further generate the anomalous easterly north of NEA influencing the meridional atmospheric motion in Eurasia. In conclusion, both of the observational diagnoses and the model sensitivity experiments show that the preceding soil moisture anomalies over North Eurasia play a vital role in affecting the large-area atmospheric circulation and further influence the summer precipitation downstream.

However, it is still not clear how the synoptic eddy activity could contribute to the seasonal-scale precipitation in NEA and related atmospheric circulation though we have observed some results that the background steering flow and baroclinity changes induce variations of synoptic storm/eddy activity. This question is definitely important to deeply understand formation dynamics of the NEA cyclonic anomaly circulation as excited by prior external factors such as soil moisture, and worthy of further studies on the next step in terms of the scale interaction paradigm between synoptic eddy and seasonal-mean flow (e.g., Ren et al. 2011, 2014).

The prediction of summer rainfall over East Asia has been a major issue in short-range climate prediction. Moreover, the forecasting accuracy of summer precipitation in NEA, especially in Northeast China, is relatively poor and has even been contrary to the actual situation in recent years (Sun et al. 2017; Zhao et al. 2020). In this study, from the perspective of land factors, we found observational evidence of a linkage between summer precipitation anomalies over NEA and late-spring soil moisture anomalies over the upstream region and confirmed these by performing numerical model experiments. The results provide a base for improving short range climate forecasts of summer rainfall over East Asia. However, the midhigh-latitude precipitation is usually affected by multiple local and remote factors. Exploration and research are needed to further quantify the amount of rainfall that can be explained by land factors such as soil moisture and surface temperature.

\section{Declarations}

\section{Acknowledgements.}

This work was supported by the National Key Research and Development Program of China (Grant no.2018YFC1506000).

\section{References}

1. Balsamo G, Albergel C, Beljaars A, Boussetta S, Brun E, Cloke H, Dee D, Dutra E, Muñoz-Sabater J, Pappenberger F, de Rosnay P, Stockdale T, Vitart F (2015) ERA-Interim/Land: a global land surface 
reanalysis data set. Hydrol Earth Syst Sci 19:389-407. https://doi.org/10.5194/hess-19-389-2015

2. Chahine MT (1992) The hydrological cycle and its influence on climate. Nature 359:373-380. https://doi.org/10.1038/359373a0

3. Dai A, Trenberth KE, Karl TR (1999) Effects of clouds, soil moisture, precipitation, and water vapor on diurnal temperature range. J Clim 12:2451-2473. https://doi.org/10.1175/15200442(1999)012<2451:EOCSMP>2.0.CO;2

4. Dai CY, Zuo ZY (2010) Relationship between previous winter and spring soil moisture and summer climate in eastern China. Meteorol Sci Technol 38:300-305. https://doi.org/10.19517/j.16716345.2010.03.005 (in Chinese)

5. Dash SK, Singh GP, Shekhar MS (2005) Response of the Indian summer monsoon circulation and rainfall to seasonal snow depth anomaly over Eurasia. Clim Dyn 24:1-10. https://doi.org/10.1007/s00382-004-0448-3

6. Ding Y, Chan JCL (2005) The East Asian summer monsoon: an overview. Meteorol Atmos Phys 89:117-114. https://doi.org/10.1007/s00703-005-0125-z

7. Dirmeyer PA, Brubaker KL (1999) Contrasting evaporative moisture sources during the drought of 1988 and the flood of 1993. J Geophys Res 104:19383-19397. https://doi.org/10.1029/1999JD900222

8. Dirmeyer PA, Schlosser CA, Brubaker KL (2009) Precipitation, recycling, and land memory: an integrated analysis. J Hydrometeor 10:278-288. https://doi.org/10.1175/2008JHM1016.1

9. Eady ET (1949) Long waves and cyclone waves. Tellus 1(3):33-52. https://doi.org/10.3402/tellusa.v1i3.8507

10. Eaton BE (2010) User's Guide to the Community Atmosphere Model AM4.0, Technical report, National Center for Atmospheric Research, Boulder, Colorado. http://www.ccsm.ucar.edu/models/ccsm4.0/cam/docs/users_guide/book1.html

11. Hoskins BJ, Valdes PJ (1990). On the existence of storm-tracks, Journal of Atmospheric Sciences, 47(15), 1854-1864. https://doi.org/10.1175/1520-0469(1990)047<1854:OTEOST>2.0.C0;2

12. Kanamitsu M, Ebisuzaki W, Woollen J, Yang S, Hnilo JJ, Fiorino M, Potter GL (2002) NCEP-DOE AMIP-II Reanalysis (R-2). Bull Amer Meteor Soc 83:1631-1644. https://doi.org/10.1175/BAMS-8311-1631

13. Kim JE, Hong SY (2007) Impact of soil moisture anomalies on summer rainfall over East Asia: a regional climate model study. J Clim 20:5732-5743. https://doi.org/10.1175/2006JCLI1358.1

14. Koster RD, Suarez MJ (2001) Soil moisture memory in climate models. J Hydrometeor 2:558-570. https://doi.org/10.1175/1525-7541(2001)002<0558:SMMICM>2.0.CO;2

15. Koster RD, Suarez MJ, Higgins W, Van den Dool HM (2003) Observational evidence that soil moisture variations affect precipitation. Geophys Res Lett. https://doi.org/10.1029/2002GL016571

16. Koster RD et al (2004) Regions of strong coupling between soil moisture and precipitation. Science 305:1138-1140. https://doi.org/10.1126/science.1100217 
17. Koster RD et al (2006) GLACE: The Global Land-Atmosphere Coupling Experiment. Part I: Overview. J Hydrol 7:590-610

18. Lawrence DM et al (2011) Parameterization improvements and functional and structural advances in version 4 of the Community Land Model. J Adv Model Earth Sys. https://doi.org/10.1029/2011MS000045

19. Li Q, Xue Y (2014) The observed and simulated major summer climate features in northwest China and their sensitivity to land surface processes. J Meteorol Res 28:836-848. https://doi.org/10.1007/s13351-014-4010-x

20. Li W, Guo W, Xue Y, Fu C, Qiu B (2016) Sensitivity of a regional climate model to land surface parameterization schemes for East Asian summer monsoon simulation. Clim Dyn 47:2293-2308. https://doi.org/10.1007/s00382-015-2964-8

21. Murray RJ, Simmonds I (1995) Responses of climate and cyclones to reductions in Arctic sea ice. J Geophys Res 100:4791-4806. https://doi.org/10.1029/94JC02206

22. North GR, Bell TL, Cahalan RF, Moeng FJ (1982) Sampling errors in the estimation of empirical orthogonal functions. Mon Wea Rev 110:699-706. https://doi.org/10.1175/15200493(1982)110<0699:SEITEO>2.0.C0;2

23. Ren HL, Jin FF, Kug JS (2014) Eddy-induced growth rate of low-frequency variability and its mid- to late winter suppression in the Northern Hemisphere. J Atmos Sci 71(7):2281-2298. https://doi.org/10.1175/JAS-D-13-0221.1

24. Ren HL, Jin FF, Kug JS, Gao L (2011) Transformed eddy-PV flux and positive synoptic eddy feedback onto low-frequency flow. Clim Dyn 36:2357-2370. https://doi.org/10.1007/s00382-010-0913-0

25. Rodell M et al (2004) The Global Land Data Assimilation System. Bull Amer Meteor Soc 85:381-394. https://doi.org/10.1175/BAMS-85-3-381

26. Ruosteenoja K, Markkanen T, Venäläinen A, Räisänen P, Peltola H (2018) Seasonal soil moisture and drought occurrence in Europe in CMIP5 projections for the 21st century. Clim Dyn 50:1177-1192. https://doi.org/10.1007/s00382-017-3671-4

27. Sato T, Nakamura T (2019) Intensification of hot Eurasian summers by climate change and landatmosphere interactions. Sci Rep 9:10866. https://doi.org/10.1038/s41598-019-47291-5

28. Seneviratne SI, Lüthi D, Litschi M, Schär C (2006) Land-atmosphere coupling and climate change in Europe. Nature 443:205-209. https://doi.org/10.1038/nature05095

29. Seneviratne SI, Corti T, Davin EL, Hirschi M, Jaeger EB, Lehner I, Orlowsky B, Teuling AJ (2010) Investigating soil moisture-climate interactions in a changing climate: a review. Earth Sci Rev 99:125-161. https://doi.org/10.1016/j.earscirev.2010.02.004

30. Shi $P$ et al (2021) Significant land contributions to interannual predictability of East Asian summer monsoon rainfall. Earth's Future. https://doi.org/10.1029/2020ef001762

31. Shinoda M (2001) Climate memory of snow mass as soil moisture over central Eurasia. J Geophys Res Atmos 106:393-403. https://doi.org/10.1029/2001JD000525 
32. Shukla J, Mintz Y (1982) The influence of land-surface evaporation precipitation on earth's climate. Science 215:1498-1501

33. Sospedra-Alfonso R, Merryfield WJ (2018) Initialization and potential predictability of soil moisture in the Canadian seasonal to interannual prediction system. J Clim 31:5205-5224. https://doi.org/10.1175/JCLI-D-17-0707.1

34. Sun L, Shen BZ, Sui B, Huang B (2017) The influences of East Asian monsoon on summer precipitation in Northeast China. Clim Dyn 48:1647-1659. https://doi.org/10.1007/s00382-0163165-9

35. Takaya K, Nakamura H (2001) A formulation of a phase-independent wave-activity flux for stationary and migratory quasigeostrophic eddies on a zonally varying basic flow. J Atmos Sci 58:608-627. https://doi.org/10.1175/1520-0469(2001)058<0608:AFOAPI>2.0.CO;2

36. Tang QH, Zhang XJ, Yang XH, Francis JA (2013) Cold winter extremes in northern continents linked to Arctic sea ice loss. Environ Res Lett 8:014036. https://doi.org/10.1088/1748-9326/8/1/014036

37. Wallace JM, Smith C, Bretherton CS (1992) Singular value decomposition of wintertime sea surface temperature and 500-mb height anomalies. J Clim 5:561-576. https://doi.org/10.1175/15200442(1992)005<0561:SVDOWS>2.0.C0;2

38. Wu LY, Zhang JY (2013) Role of land-atmosphere coupling in summer droughts and floods over eastern China for the 1998 and 1999 cases. Chin Sci Bull 58:3978-3985. https://doi.org/10.1007/s11434-013-5855-6

39. Von Storch H, Zwiers FZ (1999) Statistical analysis in climate research. Cambridge University Press, New York

40. Wang B (2006) The Asian monsoon. Springer/Praxis Publishing Co. https://www.springer.com/gp/book/9783540406105

41. Wang S, Wang S, Feng J (2016) Drought events and their influence in 2015 in China. J Arid Meteorol 34:382-389 (in Chinese)

42. Wu W, Dickinson RE (2004) Time scales of layered soil moisture memory in the context of landatmosphere interaction. J Clim 17:2752-2764. https://doi.org/10.1175/15200442(2004)017<2752:TSOLSM>2.0.C0;2

43. Xie P, Arkin PA (1997) Global precipitation: a 17-year monthly analysis based on gauge observations, satellite estimates and numerical model outputs. Bull Amer Meteor Soc 78:539-2,558. https://doi.org/10.1175/1520-0477(1997)078<2539:GPAYMA>2.0.CO;2

44. Xue Y, Juang HMH, Li WP, Prince S, DeFries R, Jiao Y, Vasic R (2004) Role of land surface processes in monsoon development: East Asia and West Africa. J Geophys Res 109:D03105. https://doi.org/10.1029/2003JD003556

45. Xue Y, de Sales F, Li WP, Mechoso CR, Nobre CA, Juang HM (2006) Role of land surface processes in South American Monsoon development. J Clim 19:741-762. https://doi.org/10.1175/JCLI3667.1

46. Xue $Y$ et al (2018) Spring land surface and subsurface temperature anomalies and subsequent downstream late spring-summer droughts/floods in North America and East Asia. J Geophys Res 
Atmos 123:5001-5019. https://doi.org/10.1029/2017JD028246

47. Yang S, He L (2013) Analysis of atmosphere circulation and weather in August 2013. Meteorological Monthly 39:1521-1528. (in Chinese)

48. Yao Y, Luo D, Dai A, Simmonds I (2017) Increased quasi stationarity and persistence of winter Ural blocking and Eurasian extreme cold events in response to Arctic warming. Part I: insights from observational analyses. J Clim 30:3549-3568. https://doi.org/10.1175/JCLI-D-16-0261.1

49. Yeh T, Wetherald RT, Manabe S (1984) The effect of soil moisture on the short-term climate and hydrology change-A numerical experiment. Mon Wea Rev 112:474-490. https://doi.org/10.1175/1520-0493(1984)112<0474:TEOSMO>2.0.CO;2

50. Zhang RH, Zuo ZY (2011) Impact of spring soil moisture on surface energy balance and summer monsoon circulation over East Asia and precipitation in East China. J Clim 24:3309-3322. https://doi.org/10.1175/2011JCLI4084.1

51. Zhang RH, Liu L, Zuo ZY (2016a) Variations of soil moisture over China and their influences on Chinese climate. Chinese Journal of Nature 38:313-319. (In Chinese)

52. Zhang R, Sun C, Zhang R, Jia L, Li WJ (2018) The impact of Arctic sea ice on the interannual variations of summer Ural blocking. Int J Climatol 38:4632-4650. https://doi.org/10.1002/joc. 5731

53. Zhang SW, Liu Y, Cao BJ, Li SY (2016b) Soil moisture-precipitation coupling and trends in China, based on GLDAS and CMIP5 products. Clim Environ Res 21:188-196. (In Chinese)

54. Zhao JH, Xiong KG, Chen LJ (2020) The causes of low predictive skills of precipitation in flood season in Northeast China. Chin J Atmos Sci 44:913-934. (in Chinese)

55. Zhou F, Ren HL, Hu ZZ, Liu MH, Wu J, Liu CZ (2020) Seasonal predictability of primary East-Asian summer circulation patterns by three operational climate prediction models. Quarterly J R Meteorol Soc 145:1089-1101. https://doi.org/10.1002/qj.3697

56. Zhou T, Zou L (2010) Understanding the predictability of East Asian Summer Monsoon from the reproduction of land-sea thermal contrast change in AMIP-Type simulation. J Clim 23:6009-6026. https://doi.org/10.1175/2010JCLI3546.1

57. Zuo ZY, Zhang RH (2007) The spring soil moisture and the summer rainfall in eastern China. Chin Sci Bull 52:3310-3312. https://doi.org/10.1007/s11434-007-0442-3

\section{Figures}



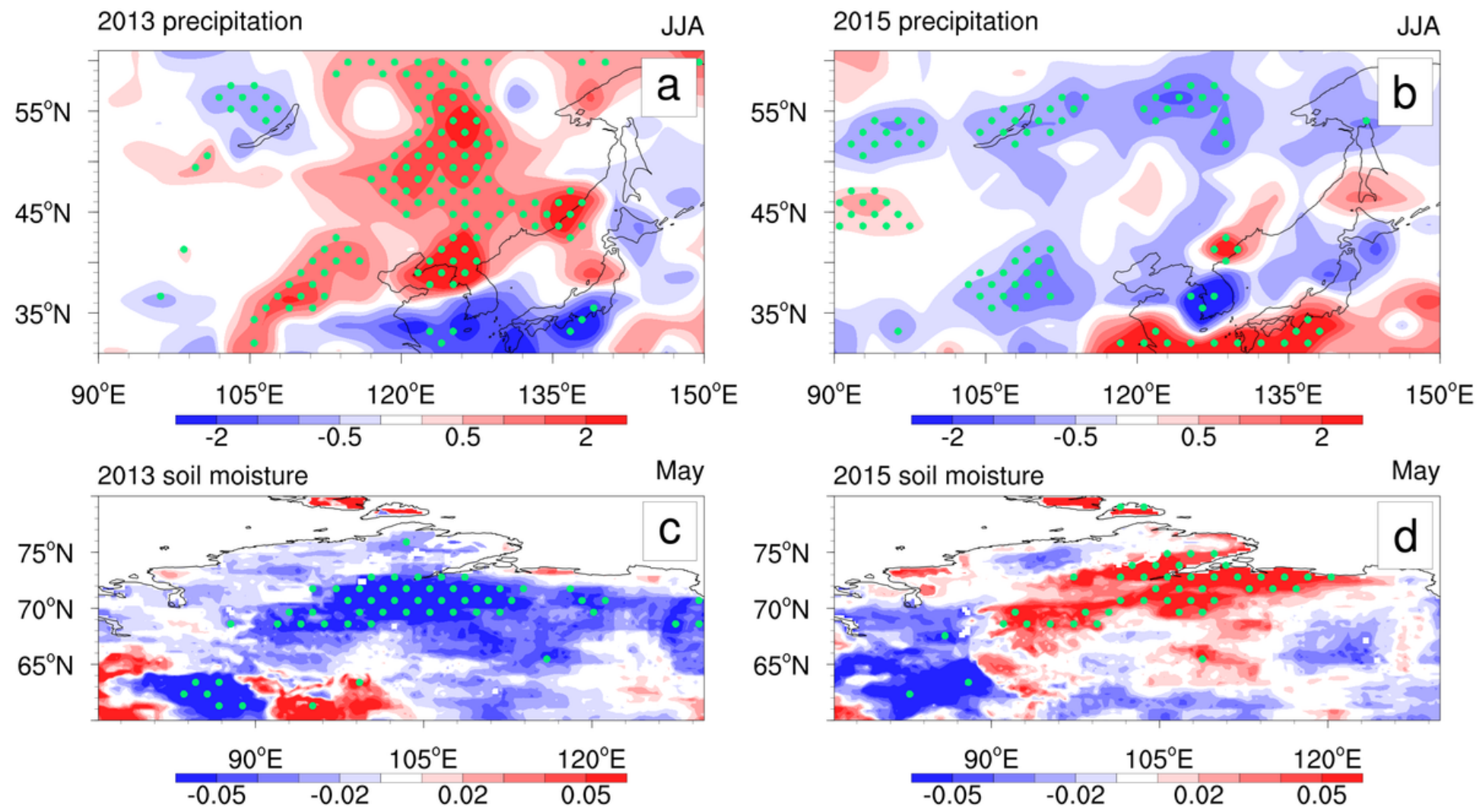

\section{Figure 1}

JJA-mean precipitation anomalies (unit: $\mathrm{mm} /$ day) over NEA and soil moisture anomalies (unit: $\mathrm{m} 3 / \mathrm{m} 3$ ) in May over North Eurasia in (a, c) 2013 and (b, d) 2015, respectively. Values that are statistically significant at the $90 \%$ confidence level are indicated by green dots. Note: The designations employed and the presentation of the material on this map do not imply the expression of any opinion whatsoever on the part of Research Square concerning the legal status of any country, territory, city or area or of its authorities, or concerning the delimitation of its frontiers or boundaries. This map has been provided by the authors. 
$75^{\circ} \mathrm{N}$

$70^{\circ} \mathrm{N}$

$65^{\circ} \mathrm{N}$

$60^{\circ} \mathrm{N}$

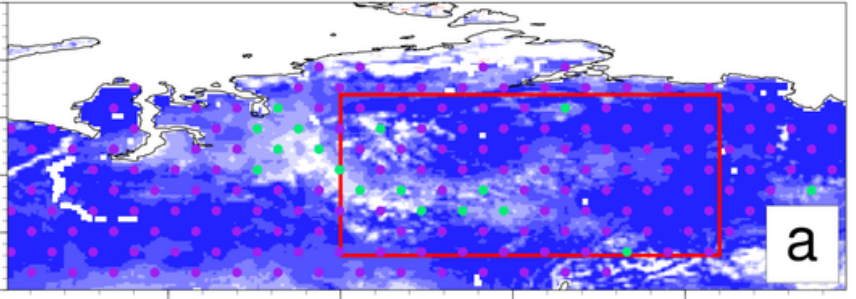

$75^{\circ} \mathrm{E} \quad 90^{\circ} \mathrm{E} \quad 105^{\circ} \mathrm{E} \quad 120^{\circ} \mathrm{E}$

SVD1 HOM: precipitation

$66.2 \%$

$50^{\circ} \mathrm{N}$

$45^{\circ} \mathrm{N}$

$40^{\circ} \mathrm{N}$

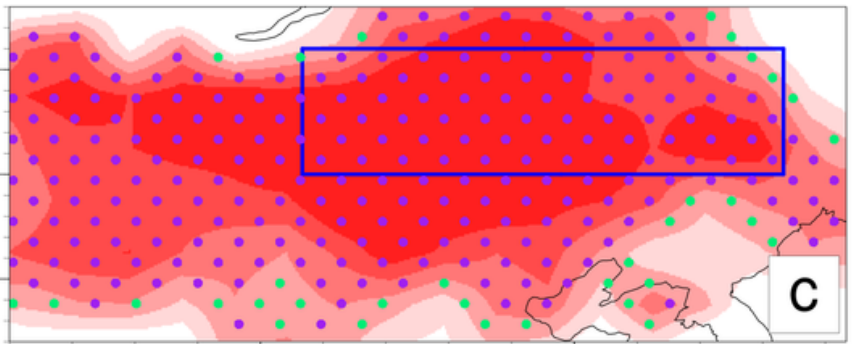

$105^{\circ} \mathrm{E}$

$120^{\circ} \mathrm{E}$

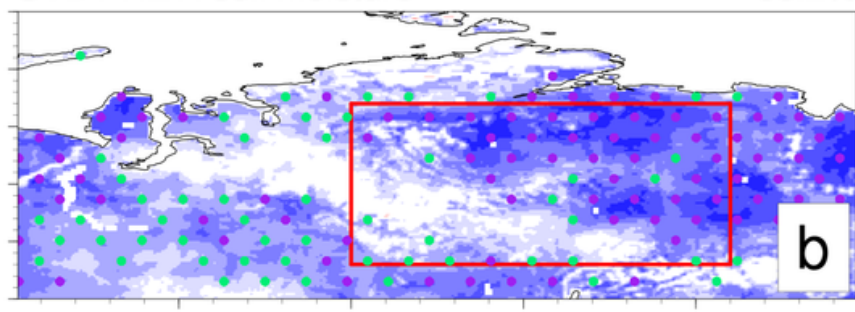

$75^{\circ} \mathrm{E}$

$105^{\circ} \mathrm{E} \quad 120^{\circ} \mathrm{E}$
SVD1 HET: precipitation

$66.2 \%$

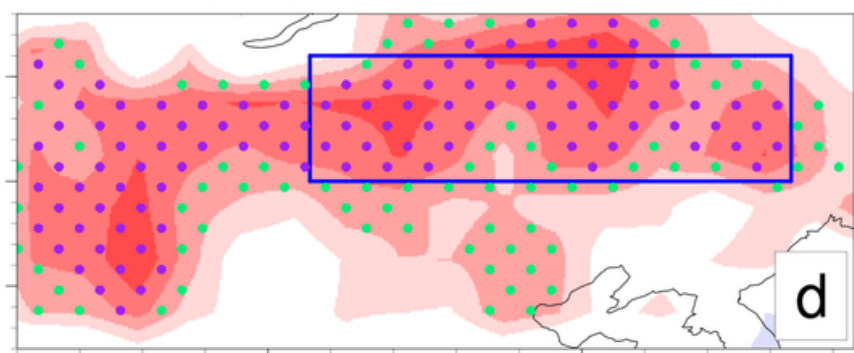

$105^{\circ} \mathrm{E}$

$120^{\circ} \mathrm{E}$
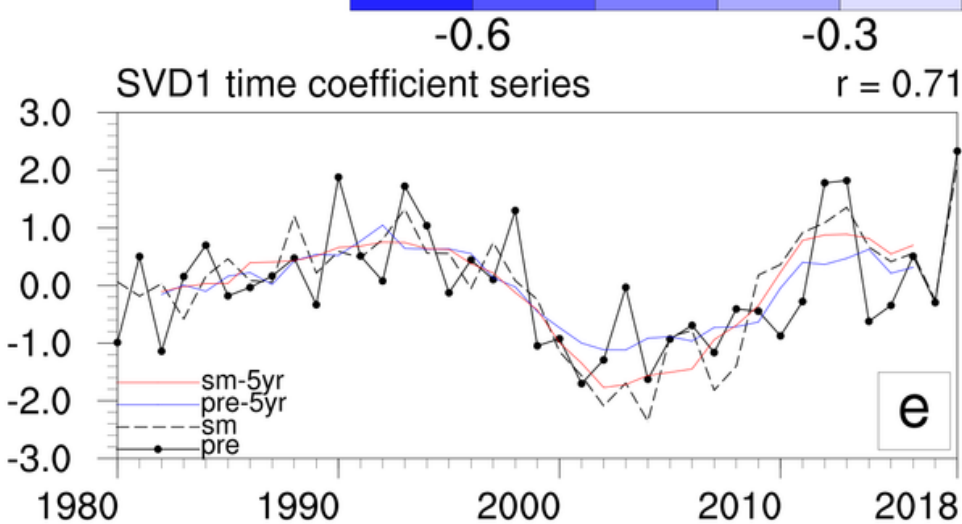

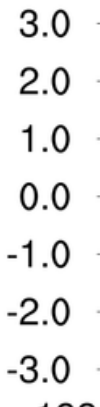

0.3

Box-averaged indices

0.6

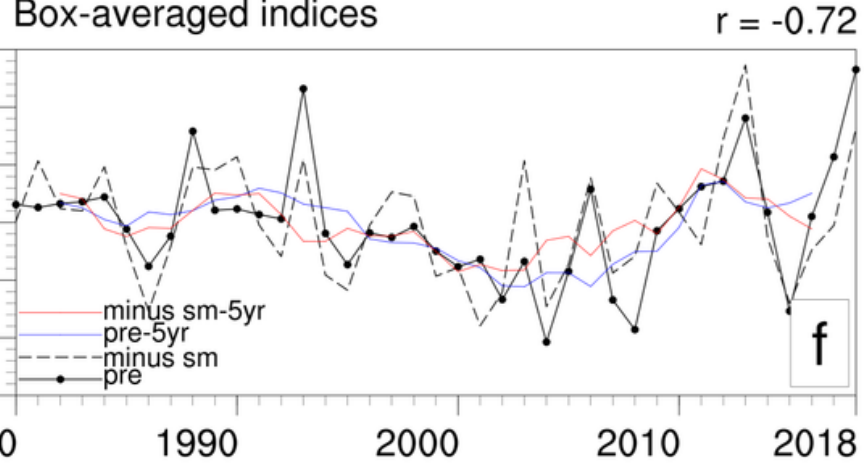

Figure 2

The spatial distributions of SVD1 (a, c) homogeneous correlations and (b, d) heterogeneous correlations of soil moisture in May over North Eurasia and JJA-mean precipitation over NEA, respectively; (e) Normalized time series of the two variables in SVD1 and (f) time series of the precipitation and minus soil moisture indices with the blue and red lines denoting their 5-year running means. Red and blue boxes in the maps denote the key regions of soil moisture $\left(58^{\circ} \mathrm{N}-72^{\circ} \mathrm{N}, 90^{\circ} \mathrm{E}-123^{\circ} \mathrm{E}\right)$ and precipitation $\left(45^{\circ} \mathrm{N}-\right.$ $\left.51^{\circ} \mathrm{N}, 107^{\circ} \mathrm{E}-130^{\circ} \mathrm{E}\right)$, respectively. Values that are statistically significant at the $90 \%$ and $95 \%$ confidence levels are indicated by green and purple dots, respectively. Note: The designations employed and the presentation of the material on this map do not imply the expression of any opinion whatsoever on the part of Research Square concerning the legal status of any country, territory, city or area or of its authorities, or concerning the delimitation of its frontiers or boundaries. This map has been provided by the authors. 
SLP
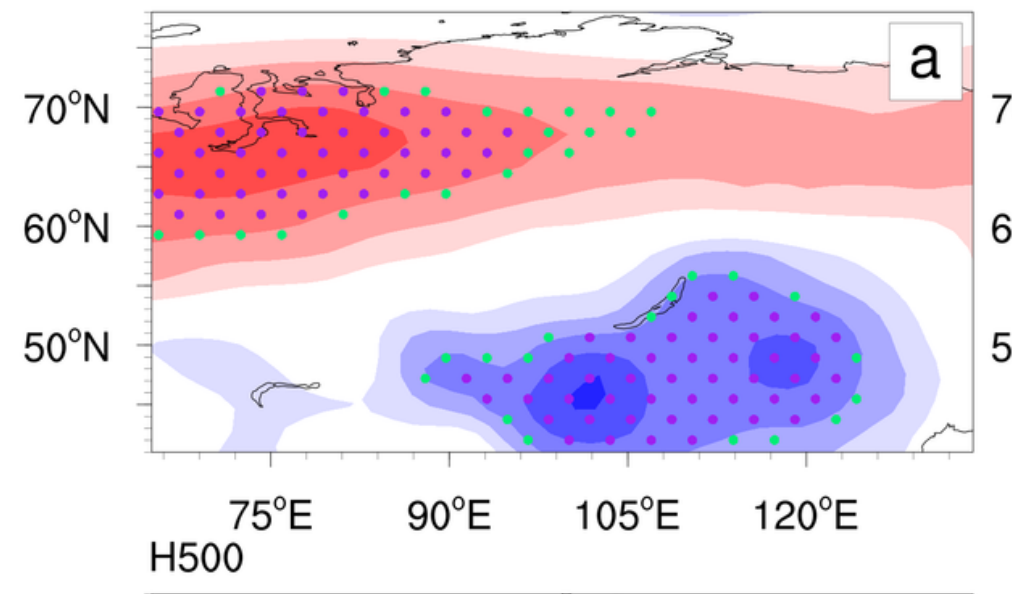

$\mathrm{H} 850$

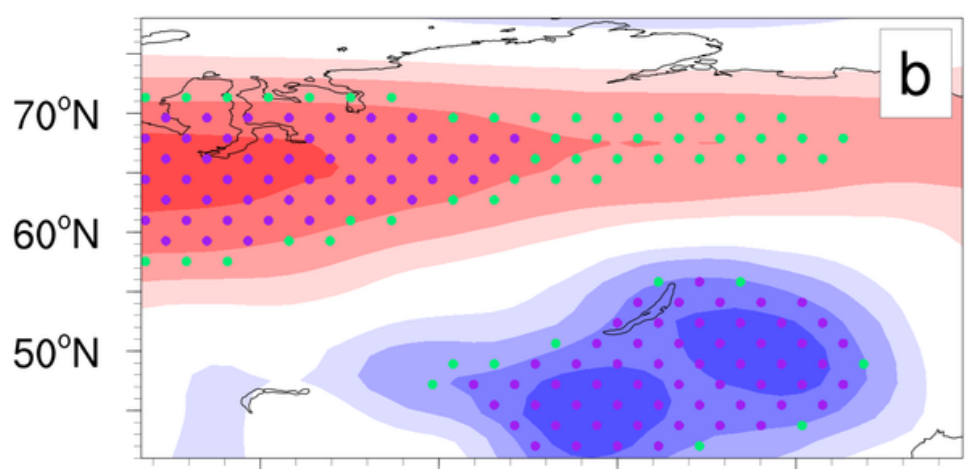

$75^{\circ} \mathrm{E} \quad 90^{\circ} \mathrm{E} \quad 105^{\circ} \mathrm{E} \quad 120^{\circ} \mathrm{E}$ $\mathrm{H} 200$

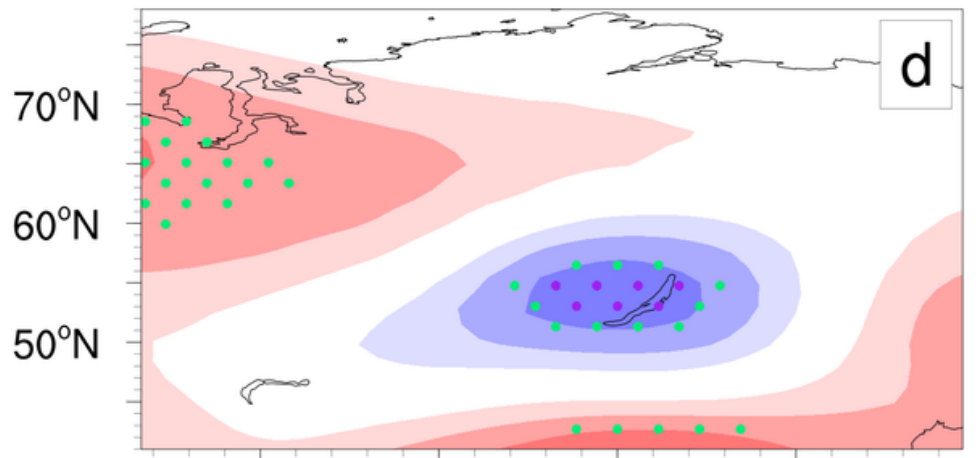

$75^{\circ} \mathrm{E} \quad 90^{\circ} \mathrm{E} \quad 105^{\circ} \mathrm{E} \quad 120^{\circ} \mathrm{E}$

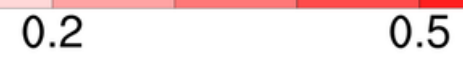

Figure 3

JJA-mean atmospheric circulation anomalies in (a) SLP (unit: Pa); (b, c, d) geopotential heights at 850, 500 and $200 \mathrm{hPa}$ (units: gpm), respectively, derived from regressions against the minus soil moisture index. Values that are statistically significant at the $90 \%$ and $95 \%$ confidence levels are indicated by green and purple dots, respectively. Note: The designations employed and the presentation of the material on this map do not imply the expression of any opinion whatsoever on the part of Research Square concerning the legal status of any country, territory, city or area or of its authorities, or concerning the delimitation of its frontiers or boundaries. This map has been provided by the authors. 
$\mathrm{U} \& \mathrm{~V}$ wind at $850 \mathrm{hPa}$

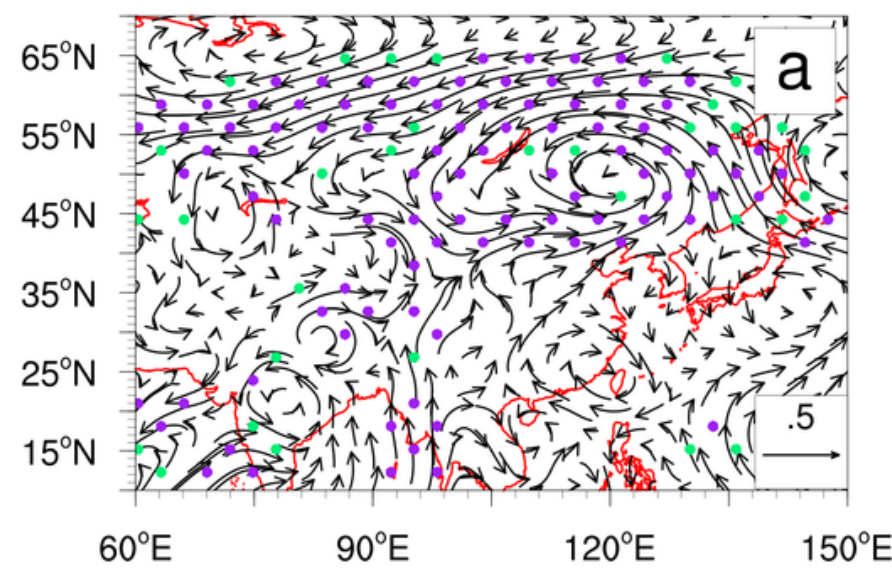

Storm track
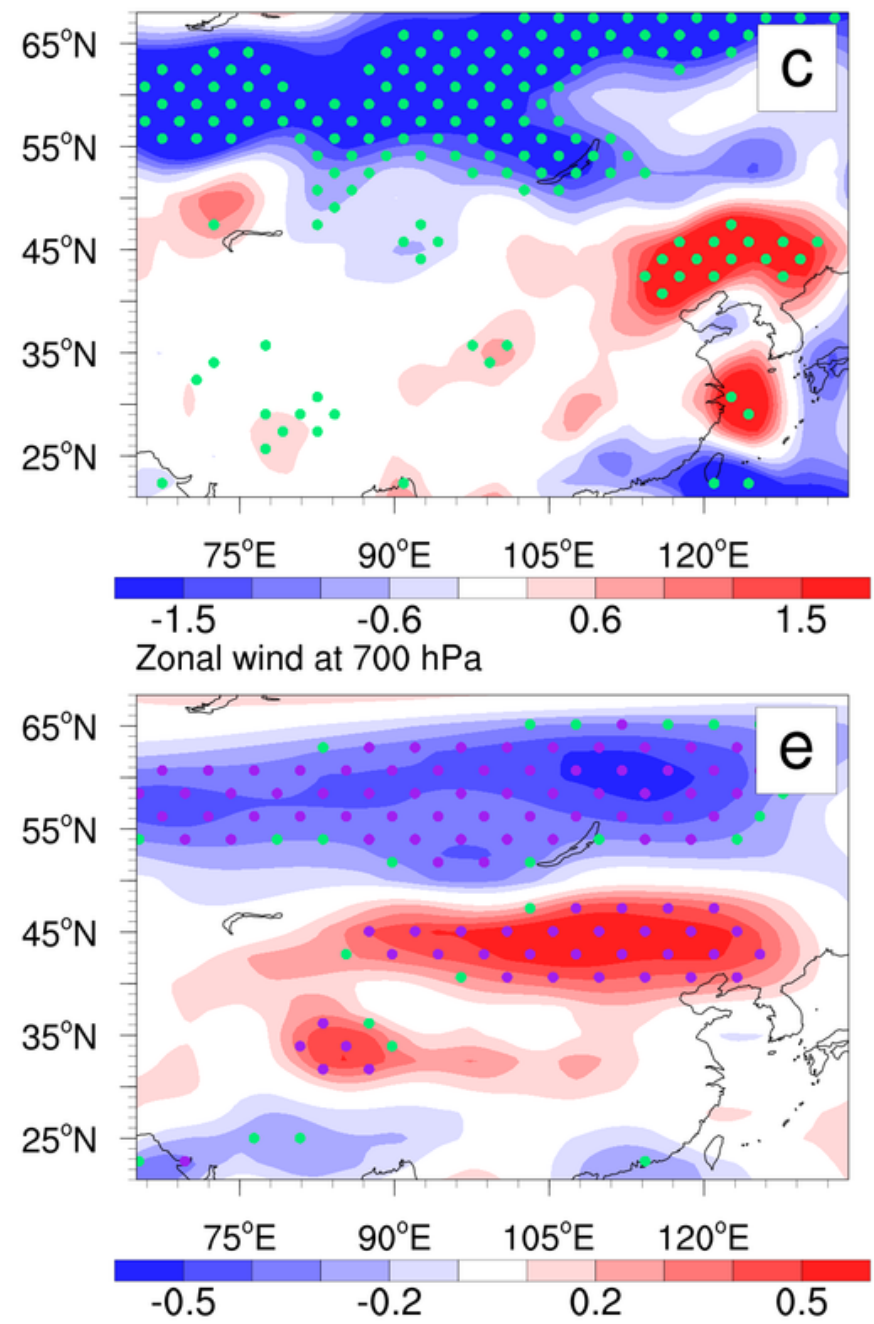

Water vapor fluxes

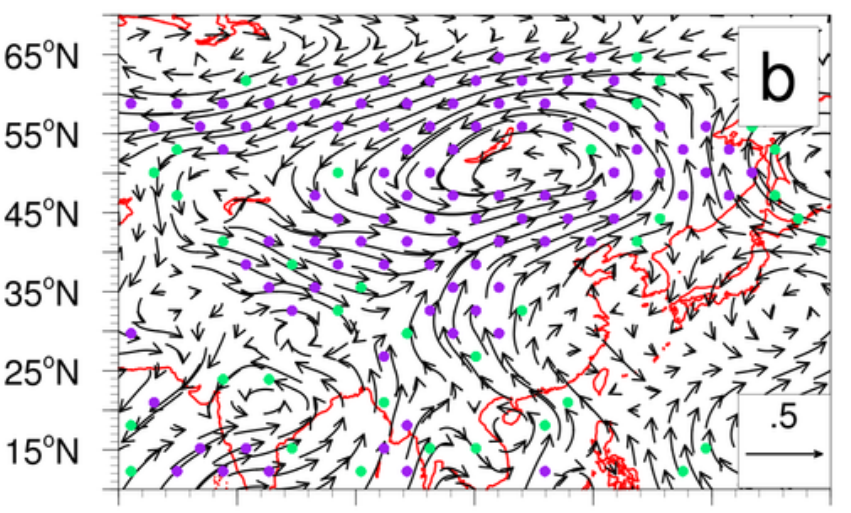

$60^{\circ} \mathrm{E} \quad 90^{\circ} \mathrm{E} \quad 120^{\circ} \mathrm{E} \quad 150^{\circ} \mathrm{E}$

Eady growth rate
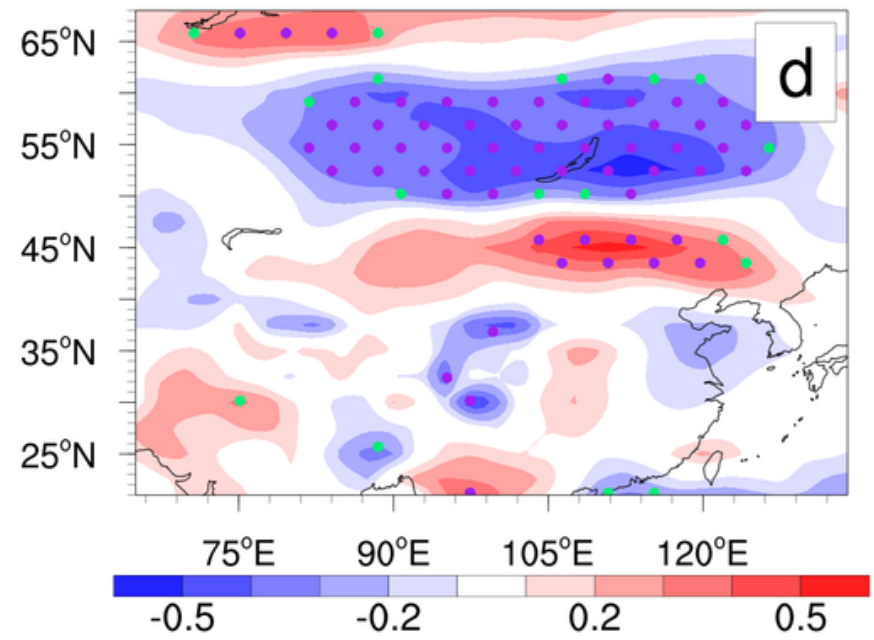

\section{Figure 4}

(a) JJA-mean anomalies of U \& V wind at $850 \mathrm{hPa}$ (unit: $\mathrm{m} / \mathrm{s}$ ); (b) JJA-mean anomalies of vertically integrated water vapor fluxes (unit: $\mathrm{kg} / \mathrm{m} / \mathrm{s}$ ), derived from regressions against the minus soil moisture index. (c) Differences of the summer synoptic-scale meridional wind variance at $850 \mathrm{hPa}$ between lowsoil moisture years and high-soil moisture years. (d) Eady growth rate (unit: 10-6 s-1) at 850-hPa in summer; and (e) JJA-mean anomalies of zonal wind at $700 \mathrm{hPa}$ (unit: $\mathrm{m} / \mathrm{s}$ ), derived from regressions 
against the minus soil moisture index. Values that are statistically significant at the $90 \%$ and $95 \%$ confidence levels are indicated by green and purple dots, respectively. Note: The designations employed and the presentation of the material on this map do not imply the expression of any opinion whatsoever on the part of Research Square concerning the legal status of any country, territory, city or area or of its authorities, or concerning the delimitation of its frontiers or boundaries. This map has been provided by the authors.

\section{Soil moisture}
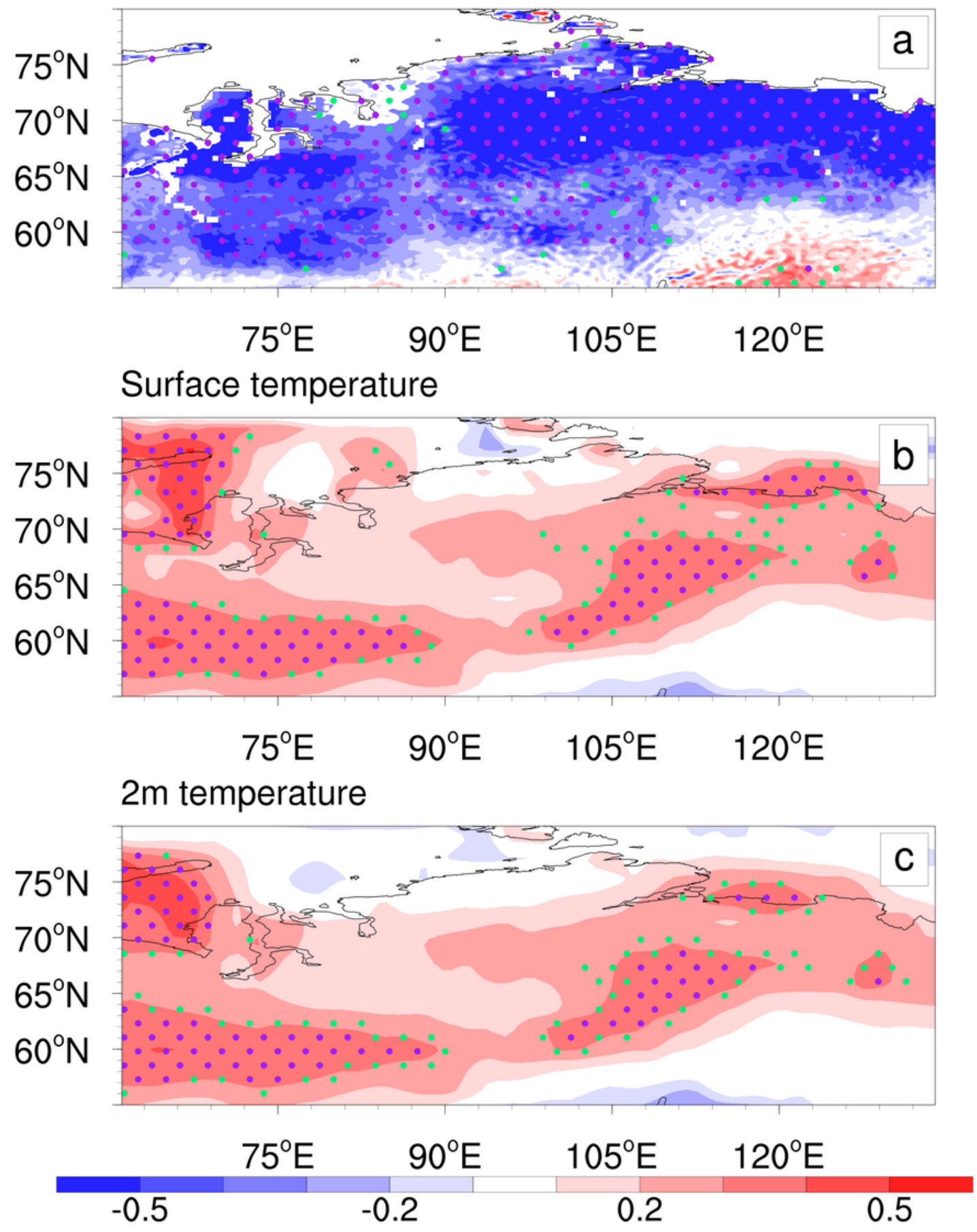

Figure 5 
JJA-mean anomalies of (a) soil moisture (unit: $\mathrm{m3} / \mathrm{m} 3$ ); (b, c) air temperatures at the surface and at $2 \mathrm{~m}$ height (units: ${ }^{\circ} \mathrm{C}$ ), respectively, derived from regressions against the minus soil moisture index. Values that are statistically significant at the $90 \%$ and $95 \%$ confidence levels are indicated by green and purple dots, respectively. Note: The designations employed and the presentation of the material on this map do not imply the expression of any opinion whatsoever on the part of Research Square concerning the legal status of any country, territory, city or area or of its authorities, or concerning the delimitation of its frontiers or boundaries. This map has been provided by the authors.
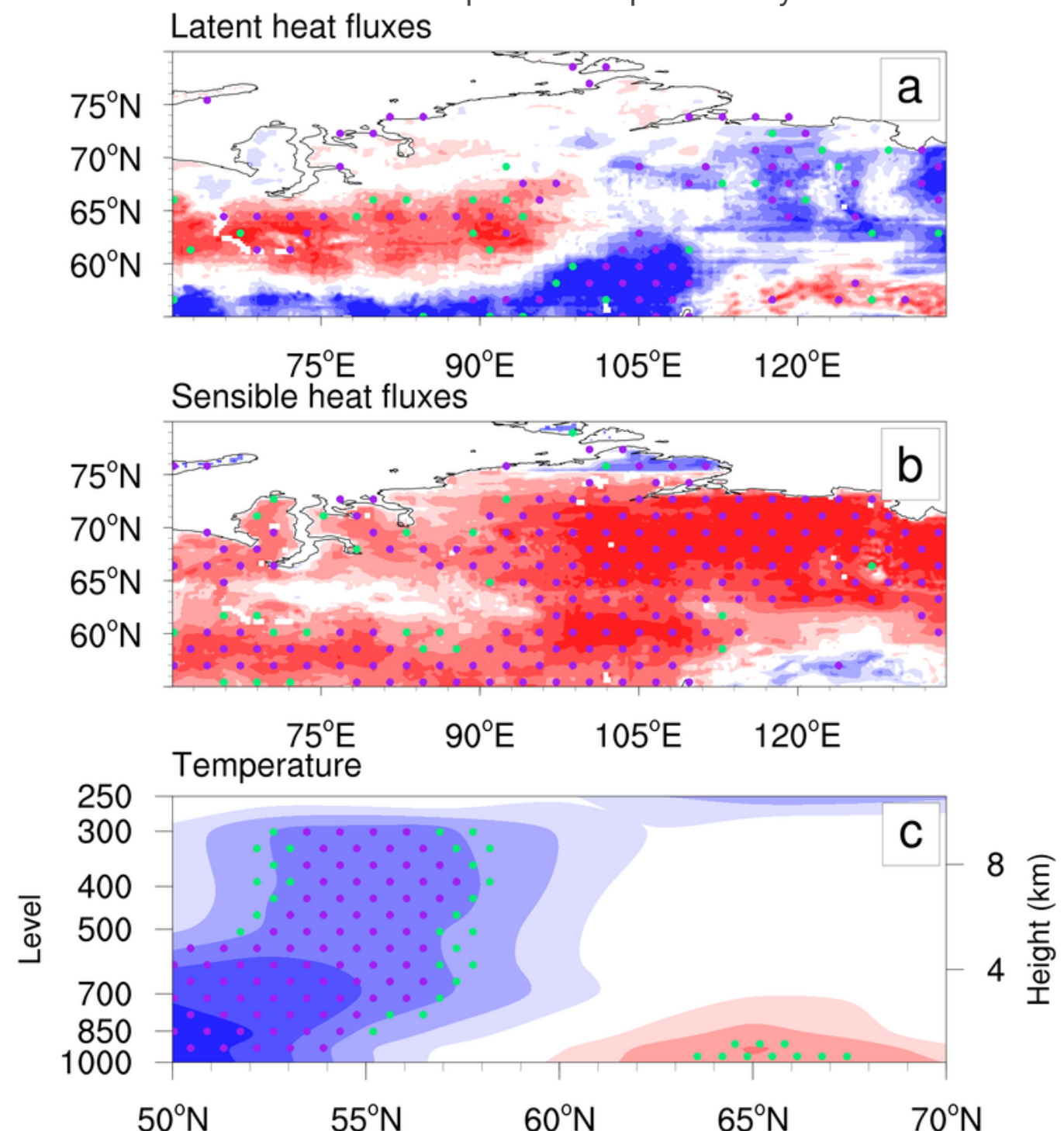
$50^{\circ} \mathrm{N}$
$55^{\circ} \mathrm{N}$
$60^{\circ} \mathrm{N}$
$65^{\circ} \mathrm{N}$
$70^{\circ} \mathrm{N}$

\section{Zonal wind at $850 \mathrm{hPa}$}

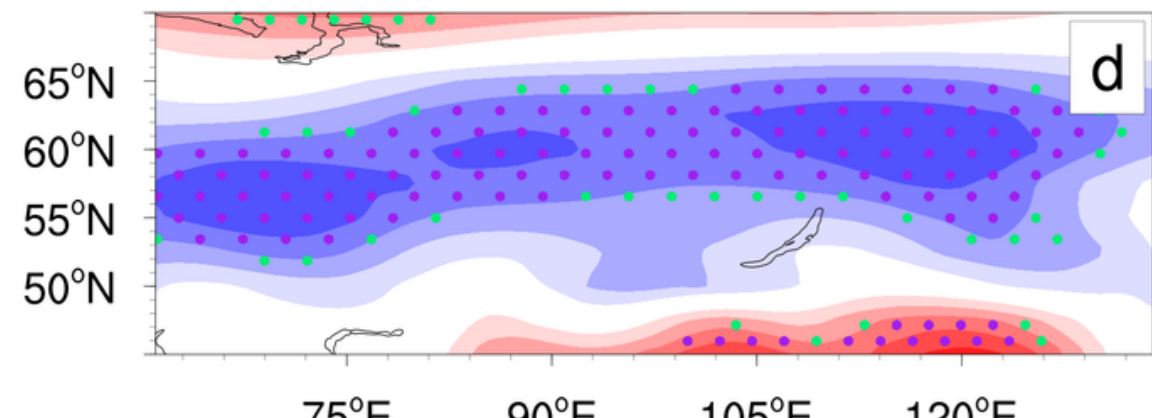
$-0.5$
$-0.2$
0.2 


\section{Figure 6}

JJA-mean anomalies of $(a, b)$ surface latent and sensible heat fluxes (units: W/m2), respectively; (c) air temperature in the latitude-height section along $105^{\circ} \mathrm{E}$ (unit: ${ }^{\circ} \mathrm{C}$ ); and (d) zonal wind at 850-hPa (unit: $\mathrm{m} / \mathrm{s}$ ), derived from regressions against the minus soil moisture index. Values that are statistically significant at the $90 \%$ and $95 \%$ confidence levels are indicated by green and purple dots, respectively. Note: The designations employed and the presentation of the material on this map do not imply the expression of any opinion whatsoever on the part of Research Square concerning the legal status of any country, territory, city or area or of its authorities, or concerning the delimitation of its frontiers or boundaries. This map has been provided by the authors. 
Precipitation

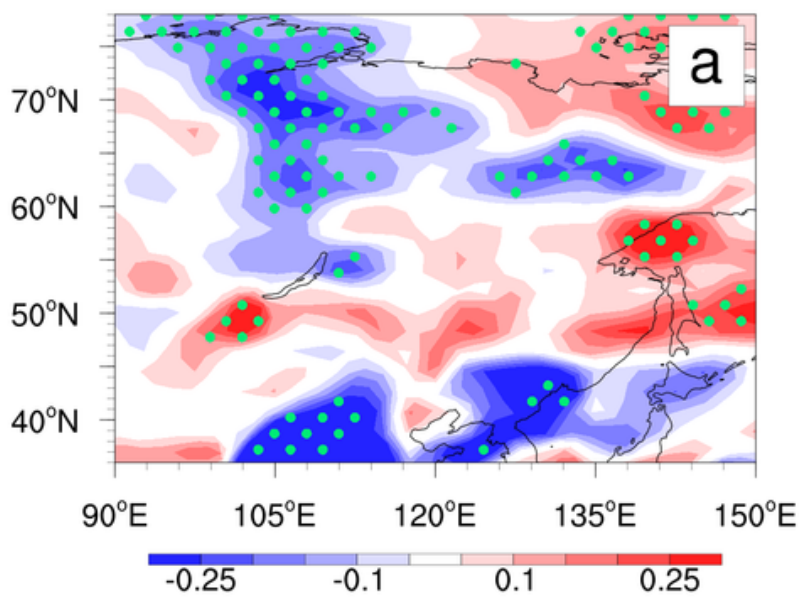

$\mathrm{H} 850$

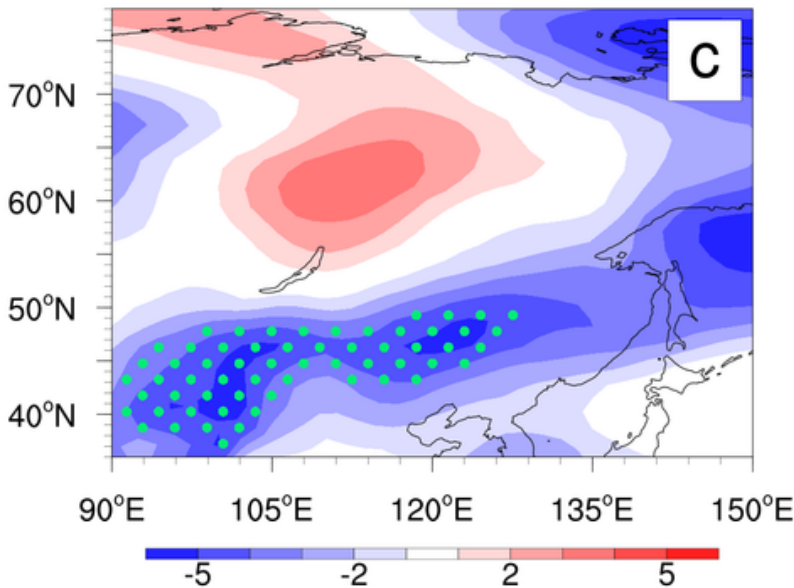

Water vapor fluxes

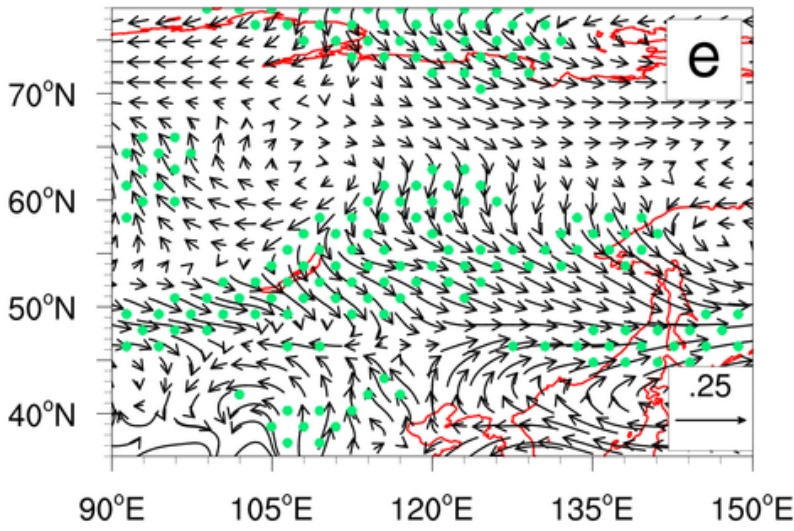

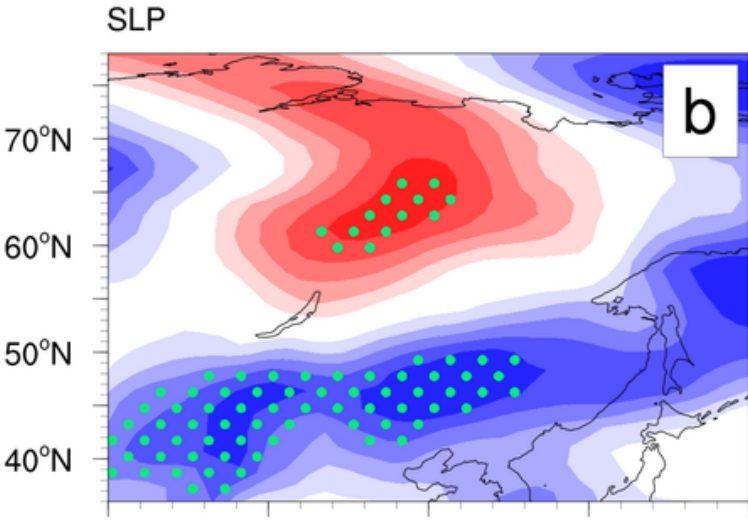

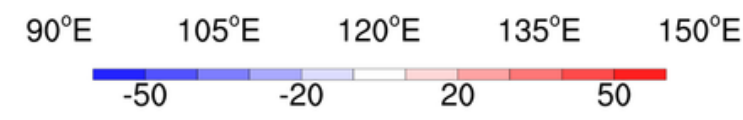

$\mathrm{U} \& \mathrm{~V}$ wind at $850 \mathrm{hPa}$

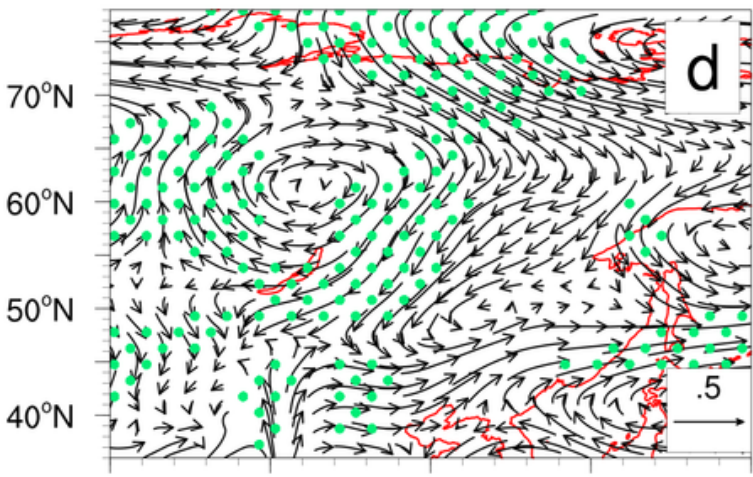

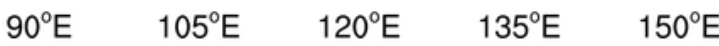

Divergences(water vapor fluxes)

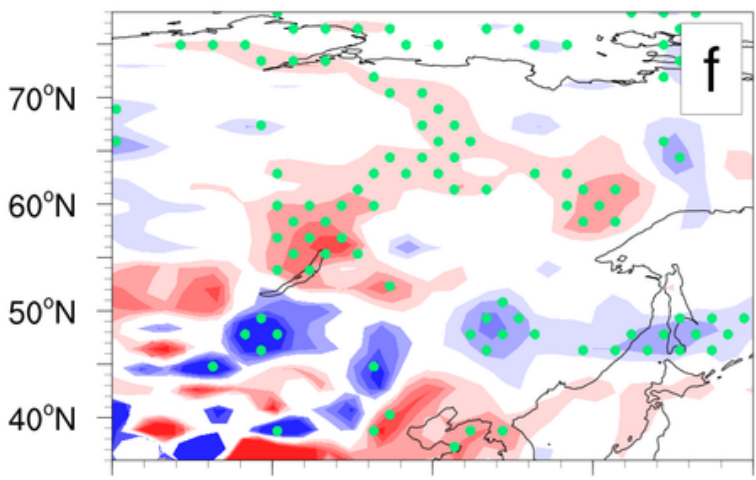

${ }^{90^{\circ} \mathrm{E}}$\begin{tabular}{cccc}
$105^{\circ} \mathrm{E}$ & $120^{\circ} \mathrm{E}$ & $135^{\circ} \mathrm{E}$ & $150^{\circ} \mathrm{E}$ \\
\hline$-5 \mathrm{e}-07$ & $-2 \mathrm{e}-07$ & $2 \mathrm{e}-07$ & $5 \mathrm{e}-07$
\end{tabular}

\section{Figure 7}

The simulated ensemble-mean difference patterns in summer between the exp_LSM and exp_HSM in (a) precipitation (unit: mm/day) (b) SLP (unit: Pa); (c) 850-hPa height (unit: gpm); (d) U \& V wind at 850-hPa (unit: $\mathrm{m} / \mathrm{s}$ ); (e) vertically integrated water vapor fluxes (unit: $\mathrm{kg} / \mathrm{m} / \mathrm{s}$ ) and (f) divergences of the vertically integrated water vapor fluxes (unit: $\mathrm{kg} / \mathrm{s}$ ). Values that are statistically significant at the $90 \%$ confidence level are indicated by green dots. Note: The designations employed and the presentation of the material 
on this map do not imply the expression of any opinion whatsoever on the part of Research Square concerning the legal status of any country, territory, city or area or of its authorities, or concerning the delimitation of its frontiers or boundaries. This map has been provided by the authors.

\section{Latent heat fluxes}

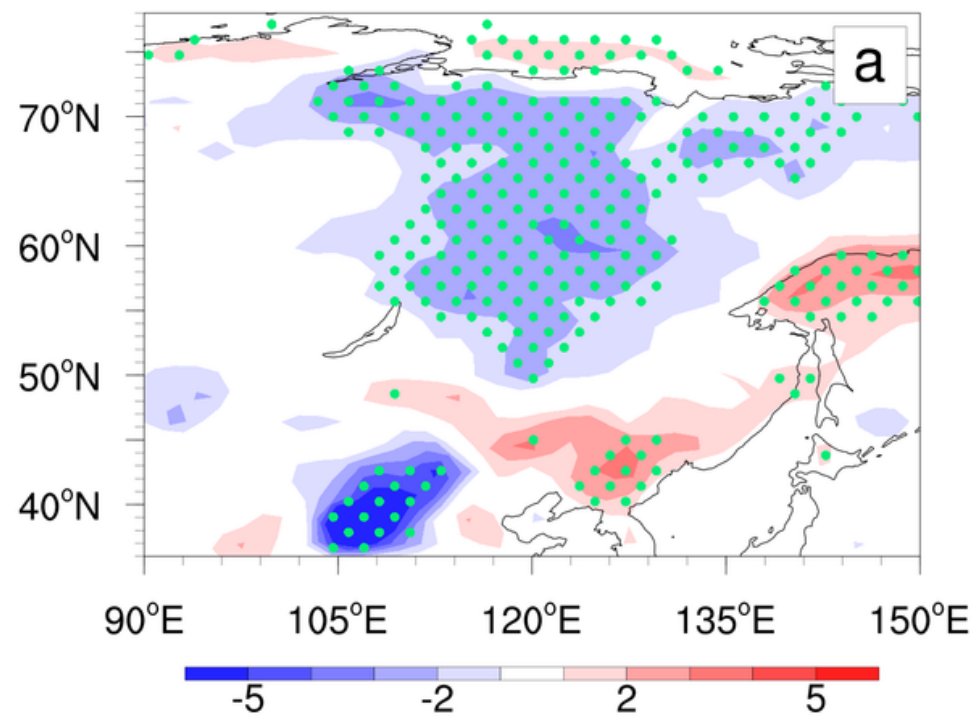

Surface temperature

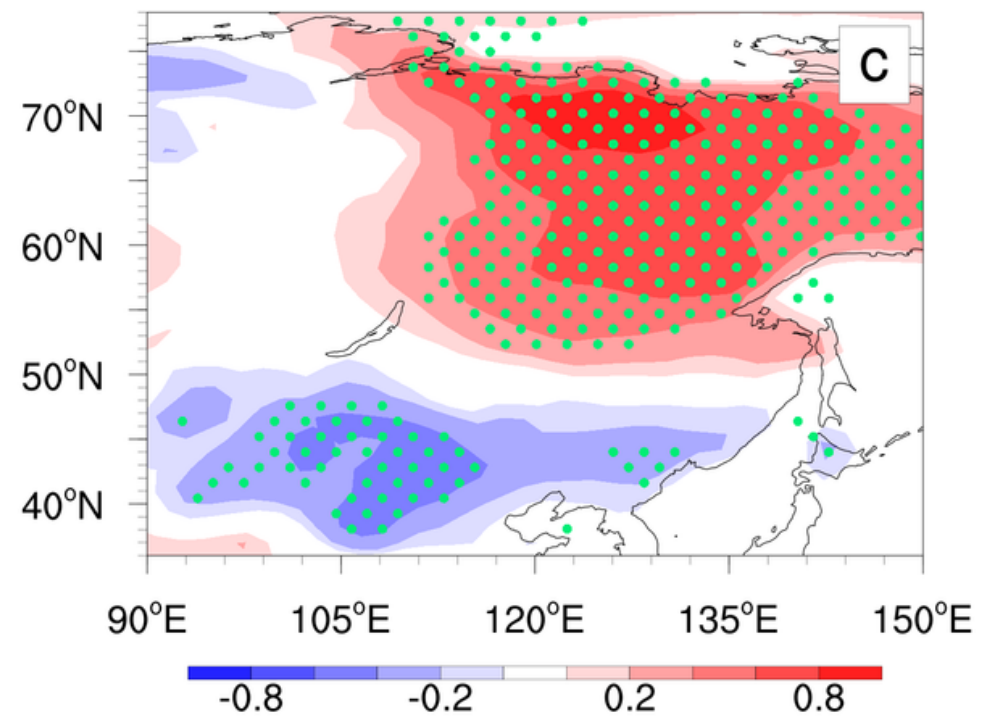

Sensible heat fluxes

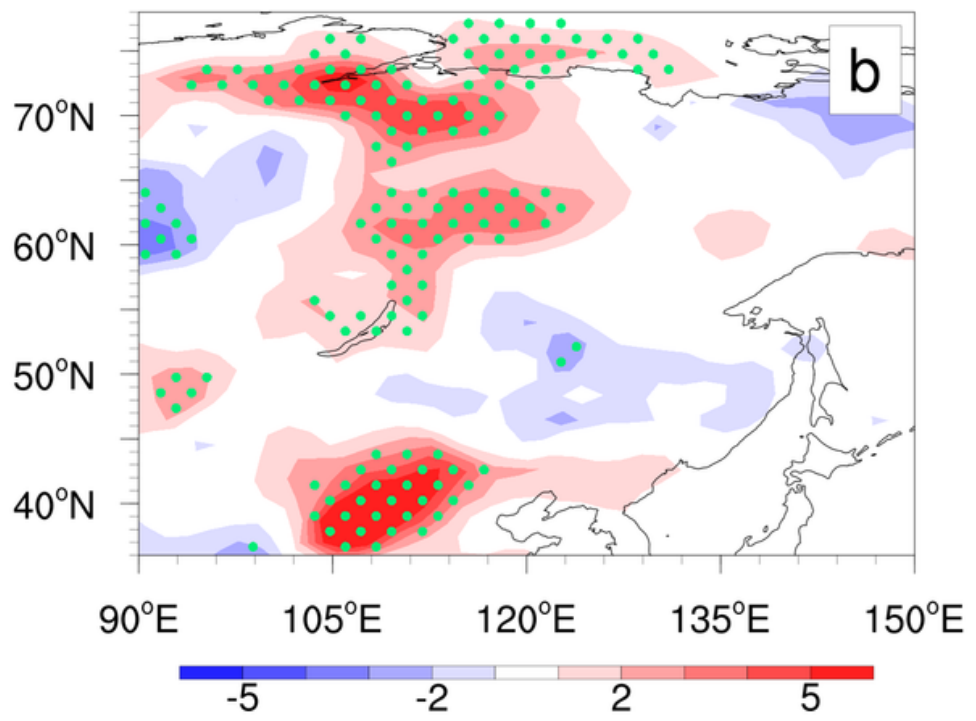

Zonal wind at $850 \mathrm{hPa}$

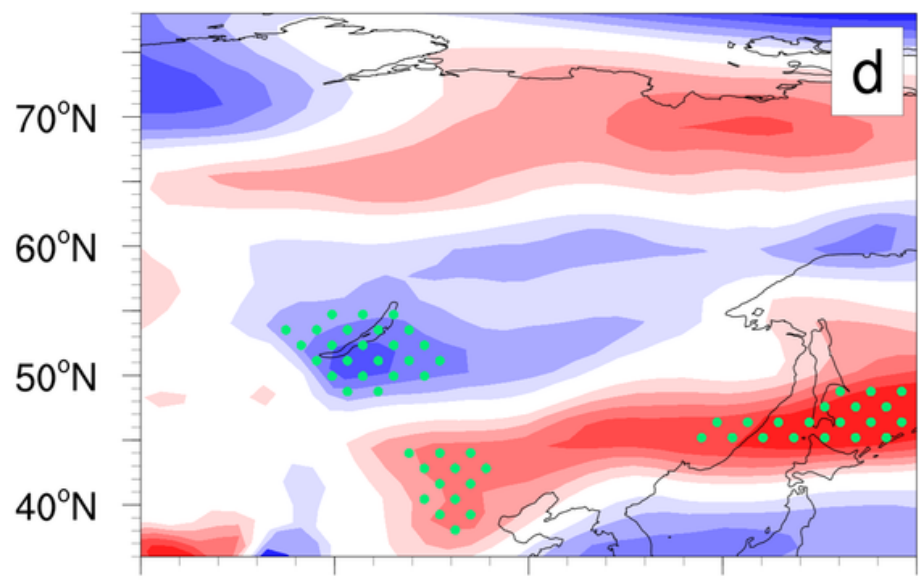

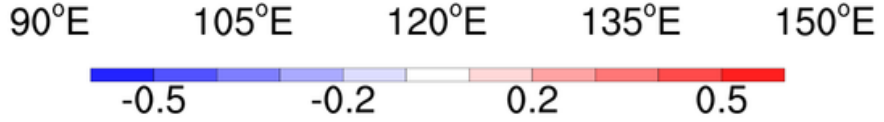

\section{Figure 8}

The simulated ensemble-mean difference patterns in summer between the exp_LSM and exp_HSM in (a,

b) surface latent and sensible heat fluxes (units: W/m2), respectively; (c) air temperature at $850 \mathrm{hPa}$ (unit: ${ }^{\circ} \mathrm{C}$ ); and (d) zonal wind at $850 \mathrm{hPa}$ (unit: $\mathrm{m} / \mathrm{s}$ ). Values that are statistically significant at the $90 \%$ 
confidence level are indicated by green dots. Note: The designations employed and the presentation of the material on this map do not imply the expression of any opinion whatsoever on the part of Research Square concerning the legal status of any country, territory, city or area or of its authorities, or concerning the delimitation of its frontiers or boundaries. This map has been provided by the authors.

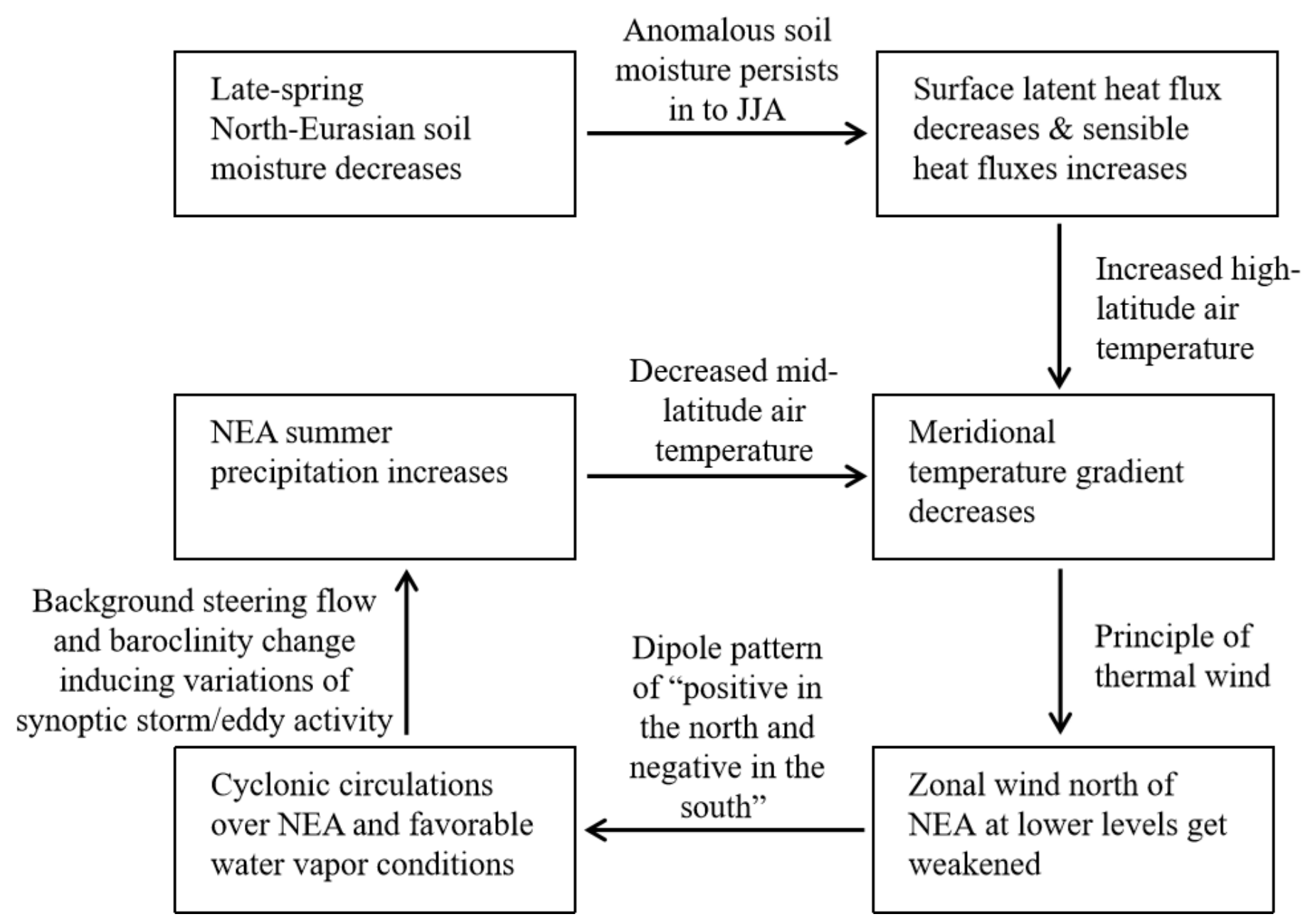

Figure 9

Schematic diagram depicting the physical processes responsible for the influence of the late-spring soil moisture over North Eurasia on the subsequent summer precipitation over NEA. 